\title{
Do You Hear Me? A Critical Review of the Voice of Racism Anti-racism Education Campaign from Aotearoa New Zealand
}

\section{Manjeet Birk ${ }^{1}$ (D)}

Received: 22 August 2021 / Accepted: 13 January 2022 / Published online: 21 January 2022

(c) The Author(s) under exclusive license to New Zealand Association for Research in Education 2022

\begin{abstract}
In July 2020 the New Zealand Human Rights Commission launched their Voice of Racism digital experience as part of their Give Nothing to Racism Campaign. On the website you can "experience" the racism felt by real New Zealanders as performed by internationally acclaimed New Zealand director Taika Waititi. The immersive campaign provides some insights into the lived experience of racism and the anti-racism action that follows in Aotearoa, New Zealand. This paper, using ethnographic and critical race methods, uses a critical and systematic review of the Voice of Racism digital experience to consider: What is the New Zealand experience of racism? How are experiences of racism curated for the general population through the NZ HRC Voice of Racism online education campaign? This article suggests the campaign employs a classic diversity logic by calling attention to racism, recentering whiteness, and completely ignoring the systemic and institutional foundations that create and sustain white settler societies like New Zealand.
\end{abstract}

Keywords Racism - Anti-racism - Education campaigns · Critical race methods . White settler societies

\section{Introduction}

Strolling through the streets of Auckland as a brown-skinned racialised Canadian during the global COVID-19 pandemic was not quite the experience I expected when my partner and I planned a year-long adventure abroad in New Zealand. Before the pandemic hit, I was a recent $\mathrm{PhD}$ graduate scheduled to start a postdoctoral research fellowship at the Auckland University of Technology. My partner, a practicing child and adolescent psychiatrist, had been hired as a locum psychiatrist

Manjeet Birk

ManjeetBirk@cunet.carleton.ca

1 Institute of Women's and Gender Studies, Carleton University, 1125 Colonel By Drive, Ottawa, ON K1S5B6, Canada 
in the Counties Manukau District Health Board, and we enrolled our 6-year-old in a French-immersion public school on Auckland's north shore. None of us are New Zealand citizens by birth, naturalisation, or marriage-we are all of South Asian descent and were born in Canada and have spent most of our lives there-but we somehow found ourselves living in the "best place to live during the COVID-19 pandemic" (Hong et al., 2021).

Had it just been for my research interests and university designation, we never would have had the opportunity to enter New Zealand during the pandemic. My research on race, racism, and systemic exclusion was not considered essential, but my partner's work as a health care practitioner was. New Zealand relies on overseas doctors, particularly for medical subspecialities (Witton \& Fuller, 2020). This allowed our small family to enter the country in July 2020 on a critical purpose visa after the borders had closed, even while when many New Zealand residents were stranded abroad. After two weeks of isolation in the government-funded Managed Isolation and Quarantine facilities outside of Auckland airport, our family emerged into a different New Zealand than the one we had visited before-a COVID elimination strategy distinctively marked our experiences in the country over the year.

I had been interested in travelling to Aotearoa New Zealand to learn about experiences of race, racism, and anti-racism in the country. Despite New Zealand's commitment to the United Nations Convention on the Elimination of Racial Discrimination (United Nations, 1996), racism is still part of the country's reality. Much like in other white settler states, there is growing local evidence that race creates a social and economic disparity for racialised New Zealanders (Aikman \& Fu, 2021; Azarmandi, 2017; Nielsen, 2021). New Zealand also has a distinct history of colonisation that includes the te Tiriti o Waitangi and the Treaty of Waitangi. Te Tiriti is the original agreement made between Māori and the British Crown. There has been a longstanding commitment by the government to uphold the promises made in the agreement, but this has been consistently breached. It has become clear that there are many deliberate miscommunications about the treaty agreement, including what it actually says, seeing as the translations between the two languages vary greatly.

Despite the commitments outlined in te Tiriti o Waitangi, Māori in New Zealand report experiencing discrimination regularly (Cormack et al., 2018; Marriott \& Sim, 2014; Reid et al., 2019). Government statistics support researchers' findings, suggesting that Māori and Pasifika children are significantly more likely to live in households with material hardship (Stats New Zealand, 2021). These realities of family poverty manifest throughout the life course with discrimination in the education system (Muru-Lanning, 2020), less representation in leadership positions, and ethnic pay disparities (Came et al., 2020). Racism also manifests through overt actions towards racialised New Zealanders, such as the March 2019 Christchurch mosque attacks (Crothers \& O'Brien, 2020) and anti-Asian racism following a global trend during the COVID-19 pandemic (Nielsen, 2021; Song \& McDonald, 2021). There is a clear link between Indigenous communities and class disenfranchisement that leads directly back to the history of colonisation. Settlers continue to profit from stolen lands and disproportionate economic benefits that accrue from intersectional factors associated with this class privilege (including access, opportunity and environmental impacts.) This situation is not exclusive to New Zealand. 
Clear evidence links colonisation to poorer social and economic outcomes across the globe. Colonisation has proven to be bad for Indigenous people globally, both historically and in the present day (Czyzewski, 2011, Health Canada, 2010). This does not mean Indigenous communities are not resilient but rather that structural barriers are stifling opportunities to thrive. In fact, Māori resilience is precisely what drew me to Aotearoa in the first place. Many of the examples I came across in my own research in Canada indicated that grassroots Māori activists are redefining sovereignty, language and resilience for Indigenous communities globally. For example, the Te Awa Tupua Act 2017 gives the Whanganui River legal personhood under New Zealand law and is often cited as a landmark for how things can be different for Indigenous communities under settler colonial rule.

I have my own racism experience, but I also wanted to understand how racism was experienced and understood in New Zealand by old and new Zealanders given the colonial context in Aotearoa. Coincidentally, my arrival in the country coincided with the launch of the New Zealand Human Rights Commission (NZ HRC) "Voice of Racism" digital experience, which was part of the larger "Give Nothing to Racism" campaign. The campaign was being heavily promoted at that time, and I was bombarded with radio coverage, social media endorsements, and posters for it. The Voice of Racism was literally calling me as an opening to understand the experience of racism across Aotearoa. In this paper I examine how the NZ HRC online campaign curated the experience of racism. After an initial overview of my methodology and of the campaign more broadly, I use critical race theory to analyse how, by recentring whiteness, the campaign reinforced mainstream understandings of racism through education without committing to social change.

\section{Methodology}

Having a connection to the Voice of Racism project from my personal experience of recently arriving in New Zealand and being keenly interested in racism, I decided to explore this campaign further. I knew that racism exists in New Zealand. Its existence is, in part, what motivated the Voice of Racism campaign. The NZ HRC received an influx of funds from the government after the violent 2019 Christchurch mosque attacks that killed 51 people and injured many more. They received these funds to deploy a second iteration of the "Give Nothing to Racism" campaign. As a result, the Voice of Racism campaign was strategically intended to focus on individual acts of racism.

Through my systematic review of the Voice of Racism project, I sought to answer the question: How are experiences of racism curated for the general population through the NZ HRC Voice of Racism online education campaign? This question also sat with me as I travelled across the country on my own New Zealand adventure, learning about cultures, communities and landscapes in relation to the Tiriti o Waitaingi during my time in the country as a racialised Canadian.

Over this time as I was navigating the ebbs and flows of the pandemic, I realised that my own body would become a site of research as I thought about how I was experiencing racism across New Zealand. With the closed borders, we were 
travelling more within the country than we had originally anticipated. The COVID restrictions allowed us to explore locally and encouraged us to spend our money in local establishments and inject a much-needed dose of life into the struggling tourism industry. This was an opportunity to truly understand how my Brown body was moving across city and regional boundaries in New Zealand and for me to see the realities of life as a racialised New Zealander. Now, this reality was very much couched in the tremendous amounts of privilege my body holds-class privilege, citizenship privilege, and a North American accent that allowed me to freely exit uncomfortable situations by effecting the familiar twang that is heard across all American TV and throughout globalised culture. While it is true that I hold this privilege, my Brown body still marked me as foreign, especially after the COVID-19 virus swept through India causing an unprecedented border closure that prevented even New Zealand citizens from entering their own country. Although I do not go into extensive detail of these experiences in this paper, they certainly informed my analysis of the Voice of Racism project.

In light of the ways the COVID-19 pandemic has reshaped a "new normal" in New Zealand and across the globe, it was imperative that my research methods reflected this new reality. It seemed appropriate to shift my research focus to incorporate digital mediums that are dominating the lived global reality. Online spaces have transformed how we connect with each other, and the many mandatory lockdowns prompted by the pandemic have intensified the transformation. Online spaces are no longer on the periphery of society but rather are an integral component of day-to-day life in New Zealand and across the globe. The Voice of Racism is a particularly interesting venue because its primary intention was to educate/inform the New Zealand public. As a result it was well situated to respond to my general research questions about context in the country. I was most interested by this campaign because, from what I understood, it was telling the stories of racism in New Zealand. As a storyteller, I wanted to better understand this story.

Delgado (2000), Bell (1992), and others use critical race theory's counter-storytelling to show us that stories can be an important and powerful way to counteract mainstream and inherited realities. Those who belong to marginal communities tell their stories or counter-stories as a way to counteract the perceived realities of the oppressive mainstream systems they inherit. This can be an important way to reflect back mainstream stories that are perceived to be true. I was interested in what might happen when a government-funded agency like the NZ HRC told stories of racism, especially given the horrific attacks after the Christchurch shooting and the international media coverage that followed this situation. I wanted to understand how institutions may or may not take responsibility for the systemic and institutional racism that is maintained by government agencies to uphold colonisation and whiteness.

I approached this campaign and its stories primarily through a critical race theory (CRT) lens. CRT was born out of legal theory, which came about as a need to understand the structural racism evident within the legal system. One of the most important components of CRT is that it offers a "framework that can be used to theorise, examine and challenge the ways race and racism implicitly and explicitly affect social structures, practices and discourses" (Dixson \& Rousseau, 2006, p. 168). There are six main tenets within CRT: (1) racism is a pervasive part of 
American (and global) society; (2) CRT challenges mainstream ideas of objectivity, colourblindness, neutrality; and merit; (3) CRT insists on a contextual and historical analysis of the law; (4) it also insists on the importance of the experiential knowledge of people of colour; (5) CRT is interdisciplinary; and (6) it works towards ending racism in an effort to end all forms of discrimination (Delgado \& Stefancic, 2000). CRT's focus is on race; however, there is an emphasis on intersectionality that also considers gender, class, and other forms of marginalisation in conjunction with race (Crenshaw, 1991).

Solorzano and Yosso (2002) discuss the ways in which CRT can be applied to methodology, what they call critical race methodology. They define this methodology as a process that (1) centres race and racism in the research process, (2) challenges mainstream discourses used to explain the experiences of people of colour, (3) provides a transformative solution to race, class, and gender discrimination and subordination, (4) centres the lived experiences of race, gender, and class of people of colour; and (5) uses an interdisciplinary knowledge base to further understand the experiences of people of colour.

To employ a CRT analysis it is also important to understand how whiteness as a systemic and structural concept fits into this analysis. Whiteness is often understood as an overarching term that includes various aspects of white identity and mainstream structures, including white privilege (McIntosh, 2003), white supremacy (Graham, 2010), and white fragility (DiAngelo, 2018), as well as the unique typology of Pākehā whiteness that exists in New Zealand (Stewart, 2020). All of these aspects of whiteness operate as systemic components that perpetuate racism and the lived experiences of racialised and Indigenous people, particularly in settler colonial states like New Zealand. This whiteness does not relate simply to the skin colour or European ancestry but rather to the damage associated with the assumption that whiteness is the norm and/or the ideal toward which to strive. This superiority informs our identities but also our experiences with systems and education.

Using these tenets of CRT I conducted a critical review of the Voice of Racism digital campaign, the Give Nothing to Racism campaign, and other online campaigns created and promoted by the NZ HRC. I also reviewed public accolades and critiques of the project. I used my understanding of race and racism as a person of colour living in New Zealand and the interpretations I made as an active member of community organisations over the course of my time in the country. Although most of my theoretical understandings of race come from a North American perspective, I was able to extrapolate the experiences of racism in a white settler country to what I was understanding about race as I worked and studied in Auckland. Although Aotearoa is smaller than my Canadian home, its population differs greatly from North Island to South Island and from urban to rural geographies. These differences are further complicated by the Pasifika, Asian, Pākehā and Māori diversity within these landscapes. Auckland alone is incredibly diverse in all of these facets, including in population from central Auckland to small rural outskirts like Pukekohe, which is a small town within Auckland's geographical boundaries. Despite this broad and diverse experience of race and racism in New Zealand, I used the CRT tenets to guide my review of the stories offered through the NZ HRC online 
educational campaigns. I wanted to know: Did the stories from the campaigns reflect the intersectional understanding of racism I had come to see/experience in Aotearoa?

Using the principles of critical race theory and critical race methodologies, I engaged with the Voice of Racism campaign website three times a week over the course of a month. The multiple points of entry to the website allowed me to engage with the material based on where I was at mentally, emotionally, and spiritually each day. Although the website and the materials on it did not change from day to day, my engagement with it was different based on my personal state on the given day, making each engagement unique and fresh in its own approach. This approach also allowed me to engage with "felt theory" (Million, 2009) to see how this "Voice" was making me defend, engage, or disengage on every occasion. Each time I approached the website, I asked myself the research question and took notes about what the website was telling me about the "lived experience" of racism in New Zealand. Each time I engaged I was fully aware that the materials that were available on the website had been curated and created through a particular lens to share a unique story through the perspective of the NZ HRC. Although the Voice was informed by the interviews the Commission conducted, there was little information available about what types of stories they acquired, who they interviewed, and how they translated those stories into the Voice. I created detailed field notes based on my encounters with the Voice over the month. After collecting the field notes, I reviewed online and readily available critiques and accolades regarding the Voice of Racism campaign. Through this review I sent a series of emails to the Tāmaki Treaty Workers collective, which had communicated their critiques of the campaign directly to the Commission. Some of their email replies to me are referenced throughout this article.

\section{My Experience with the Voice of Racism Campaign}

As I sit down to engage with the Voice of Racism project, I can feel the intensity of what I am about to do even before I begin. I type in the URL and I am immediately taken to a dark navy blue webpage with vibrating royal blue lines that shoot across the screen. The silvery gray writing and emblems of the campaign stand in stark opposition to the dark backdrop. The ominous darkness is the total opposite of the Google search homepage screen and the generally white backdrop I have come to expect from webpages. The darkness feels assaulting. Upon clicking "enter" a warning appears: headphones recommended. I rifle through the bottom of my bag looking for them. I am all alone in my apartment, but somehow the warning makes me self-conscious. I don't want other people to hear. Racism has always been a quiet and private journey in the past. I am reminded it should stay that way. I slowly put the headphones in and turn the volume down. All the buildup has left me afraid of the assault to come.

After putting in my headphones I notice the sounds associated with the website. I make out the sound of vibrations and a heartbeat in the background. Sounds I didn't notice before I put my headphones in. It's meditative but also a little ominous. Have they always been there? I can't be sure. Press \& hold, the command says. I do. 
Immediately the bluish vibrations turn to the image of a partial face: a muscular jaw, lips, and nose. The blue lines have become blood red. The Voice speaks: "They are looking at you weird-they think you are strange." I let go and the face disappears. The blue lines and heartbeat return. In the bottom left corner a question: Why is this racist? I push it. "This is an example of internalised racism. What can you do instead? Understand the harm of internalised racism." I click on the "more" button. On the left side a list of the "examples": racist stereotypes shared from "real experiences" on the right.

Understand the harm of internalised racism. When people accept society's negative beliefs about their culture and race, this can lead to low self-belief and negatively affect their health and wellbeing. Ongoing exposure to negative stereotypes, stories and statistics about your race, and to the negative actions and words of other people, can have a harmful effect over the course of your life. Research shows these internalised effects can have physical health outcomes including avoidable disease and early death. Make a commitment not to add to this harm in others, and show care with your words and actions. (New Zealand Human Rights, 2020b)

The education campaign by the NZ HRC is providing a series of definitions without a thorough understanding of how this definition operates in daily society. There is a lack of understanding that racism is not simply a characteristic that lives in individuals but rather a pervasive part of society that is enacted through the systemic internalisation of these principles implemented through policies fueled by systemic racism, and colonisation. The assumption that one could "make a commitment not to add to this harm" ignores the impact of racism and does not make an intersectional analysis of how systems perpetuate the complex entanglement of racism as a systemic scaffolding that positions some people with power and others without. I discuss this further later in the paper.

As I am using the website I have an interaction with a digital man who appears from the lines on the screen and is performed by internationally acclaimed New Zealand director Taika Waititi. The face appears from the blue vibration lines on the website. The website asks you to press and hold to engage in the experience. I hit the back button. Again I press and hold. The face is back. "Why should you be treated any differently?" "This is an example of ignoring race." I go back.

This time I press and hold for a couple of minutes. The man comes back at me over and over, hurling insult after insult. Most slide off my back. They are things I have heard before, and some I have not. Mostly they do not impact me. But one example stings a little. Takes me back to my own childhood trauma events on the playground. Even to my inner monologue as I roam the earth. Things I say to myself, things that upset me. "Why is this racist?" I hit the button. This time a long list appears showcasing examples of "rejection of other cultures," assumptions of nationality, ignoring race, unconscious racism, stereotypes, verbal or physical abuse, assumptions about criminality. Putting on my educator hat, I go up and down the list. They have done a pretty good job of being thorough about the types of racism. And then the reminder: "Press this icon if you feel distress." The image of a heart with a handshake within it. I click on the icon to open a series of helplines and 
resources, including a Māori and a Pasifika specific resource. Help is never too far away, the webpage reassures.

\section{Findings: Recentring Whiteness and Ignoring Institutional Racism}

Much like other public education campaigns, the Voice of Racism project opened to mixed reviews. Some felt the digital platform finally gave voice to the experiences racialised New Zealanders have on a day-to-day basis (TVNZ, 2020). Others felt the campaign fell short of the complicated reality of racism in Aotearoa and ignored the most damaging aspects, including institutional racism (Tāmaki Treaty Workers, November 2020, personal communication).

My own experience of immersing myself in the project for the first time was powerful. The website has incredible audiovisual and production quality, and it was immediately clear the campaign was well funded and had involved many digital experts. As a result, the experience is incredibly immersive. I can imagine that, for a person who has never experienced racism firsthand or thought about it for an extended period of time, it could be transformative to literally "experience" racism in such a way.

The project does a relatively good job defining the various forms of racism and including clear examples. The use of a celebrity, Taika Waititi, is an important draw, and the campaign reports a positive and lasting association with Waititi (Alex van Wel, January 2021, personal communication.) As a result, the experience is likely a powerful opportunity for people with little understanding of racism and discrimination to fully engage with aggressive forms of racism and microaggression that racialised and Indigenous communities experience on a regular basis across Aotearoa New Zealand.

Although the campaign has done a relatively good job defining some forms of racism, including personal racism, microaggressions, and stereotypes, amongst others, noticeably absent are systemic and institutional forms of racism, arguably the most powerful and potent forms of racism. There are some cursory references to the more sedimented forms of racism, yet there is little acknowledgement of or connection to how these larger and more ingrained forms of racism contribute to the smaller acts of everyday racism. Furthermore, although there is a clear connection to Māori communities, there is no clear connection made to historical and ongoing colonisation and the ways that dispossession of land has fuelled and continues to fuel racist rhetoric in Aotearoa.

It is clear that the educational campaign was intended to target Pākehā communities as opposed to aiming for a dramatic shift in the ways in which organisations and systems are governed. This is made clear by the lack of solutions suggested to address any kinds of systemic changes. In maintaining an individual approach, the campaign also reinforces damage-centred narratives (Tuck, 2009) by suggesting that there is an individual component that can be rectified through individual action (from both the racialised and Pākehā standpoint) as opposed to a governmental and institutional responsibility to shift organisational dynamics that would dismantle white settler systems of power. This is not simply a New Zealand issue. Many 
have written about how governments, including my own, the Canadian government, diffuse their settler responsibilities through education programs that reinforce mainstream understandings of race and racism and absolve responsibility through "diversity" programs that do little to shift or change the lived reality of racialised, Indigenous, and marginalised communities (Birk, 2021; Razack, 1998; Thobani, 2007).

Other glaring absences include a clear communication of the methodology employed in collecting the data that informs the Voice. The website thanks "those who shared their real experiences for this project." However, there is no explanation of who these people are, where they live, how they shared their information, what they actually said, and how they expected their stories would contribute to this project. There is also no engagement with what they might have anticipated or expected from their participation or whether they felt like the project accurately reflected their contribution. Some sort of evaluation criteria from the participants would have been helpful to understand whether they felt as though the voice that was created accurately reflects their experiences. The "About" section says that 200 people shared their experiences and that their stories were amalgamated to create the Voice of Racism. There are no other mentions of the people, the methodology, etc. Again, this lack of information ignores the localised nature of racism and the ways in which individual racism interacts with and informs systemic racism. All these gaps and questions leave me reeling.

\section{Individual Actions}

The Voice of Racism project was the result of government funds in response to the Christchurch mosque attack. Because it was reacting to this tragic attack "a strategic decision was made to focus on personal harm" (Alex van Wel, January 2021, personal correspondence) throughout the Voice of Racism project. Alex van Wel, Communications Manager for the NZ HRC explained, "We wanted people in New Zealand to understand how they may be contributing to racism and to encourage them to be part of dismantling it" (personal communication, January 19, 2021). By this logic, white New Zealanders would be committing to "experience" racism as a part of dismantling it. This logic is flawed. We all experience racism everyday because it is a pervasive part of society. We do not need to be on the receiving end of a racial slur in order for that to be the case. I do not need to be called a terrible name to understand that it is hurtful. This is the assumption steeped in white logic that sets up white bodies as the saviour, that white people have the power to save if we just "make a commitment not to add to this harm in others." But not adding harm is insufficient in dismantling the racist and colonial system that created this harm in the first place.

Whiteness as a systemic and structural concept informs the basis of the Voice of Racism campaign, despite the fact that individual racialised and Māori people may have been involved with developing this campaign. Regardless of the campaign creators, the dominant assumptions of whiteness as the norm and/or ideal goal informs the ways in which the campaign was designed. This is clearly evidenced by the lack 
of information available about the stories that were gathered to create the campaign. Without a clear intersectional and geographical awareness of the participants who shared their stories, we are further erasing the effects of racism by reproducing the same stories for the purpose of whiteness, as consumers or like Stewart's (2020) Pākehā vampires. This consumption ignores the situational and systemic aspects of identity by reducing it to a phrase that tells the whole story. A phrase like "Why should you be treated so differently?" spoken by the Voice of Racism and divorced from the racist scaffolding that dominates the everyday lives of Indigenous and racialised peoples.

In the campaign's supplemental materials, which encourage viewers to "do more," there is an emphasis on the \#SupportRecordReport campaign. This campaign encourages people to be active bystanders and engage in racism by taking action. I find this campaign even more problematic than the Voice of Racism campaign. It completely ignores the systemic/power elements at play in racist actions and suggests that one can "ignore" racism, which encourages a very problematic white saviour complex. This dynamic is clearly exemplified by Stewart's (2020) Pākehā typology of the saviour. Suggesting that one can "ignore" racism minimises the felt realities of experiencing aggressive and microaggressive acts and reduces the experience of racism to a "mean thing that happens." There are multiple layers at play when dealing with racist acts that cannot simply be ignored, including the lived reality of racialised people that have accumulated a mountain of these aggressive and microaggressive acts over the course of their lifetimes. To suggest that they can be ignored trivialises the long-term effects that racism has on the bodies of people of colour, especially as they relate to mental health (Paradies et al., 2015).

Overall whiteness and mainstream ideology created the foundation for the Voices of Racism project. Even though the goal of the project is to reflect the everyday lived experiences of people of colour, the project still falls into the paradigm of centring the expectations and needs of white people and thus recentring whiteness. This campaign is geared towards bystanders and provides them with actions they can take to address racism when they see it. It centres individual acts, such as witnessing a racist insult on a bus, and showcases the ways the bystander (likely but not exclusively a white person) can stand in solidarity with the person of colour who is experiencing an aggressive racist act. I am not suggesting that bystander intervention is not helpful in this type of situation, but drawing attention to a hashtag campaign of this nature fails to acknowledge the complex and complicit history of Pākehā and other settlers and how this very act ignores the larger issues of racism and power. These types of campaigns are intended to centre the experiences of racialised people yet still somehow manage to recentre the whiteness that created the situation in the first place.

\section{Contradictory Campaign: Satisfying Diversity}

In the opening lines of the Voices of Racism project's "About" section it says, "Everyday in Aotearoa, people experience racism which hurts them, prevents them from reaching their potential, or from living their lives feeling welcome and secure." So, 
the Commission "calls everyone to listen to the Voice of Racism, to understand the experience, to appreciate the harm, and learn how to silence racism." You scroll further down and you see that the Voice of Racism project is part of the larger "Give Nothing to Racism" campaign. The website explains that

racism lives in our everyday words and actions, our systems and our practices. To stop it growing we must begin by acknowledging and confronting where it exists in ourselves and others. Then give it no tolerance, no power, no welcome, no acceptance, and no voice. Give nothing to racism.

As a viewer, user, and person who has sought to actively engage with this campaign to understand the experiences of racism in New Zealand, I am left confused. The Commission has developed a contradictory campaign. On one hand, they say to give racism no voice, and on the other hand they have literally created the voice of racism and ask that you "listen to the voice." So, which is it? No voice, or listen to the voice?

I continue to search through the "More" sections of the website. I notice a thread in the stereotypes: "Silence racism by challenging and rejecting racial stereotypes. Seek new information and media sources that will help you avoid stereotypical narratives and assumptions." Fairly sound advice, but I cannot help but wonder if this entire program is doing anything but? How can the Give Nothing to Racism campaign give so much to racism by literally amplifying the voice of racism? Putting the red, strong-jawed face directly into my ear and mind. Doing the very opposite of what has been suggested by giving everything to racism, by allowing it to come in.

I go a little further into the website and I notice some of the links they have suggested, including a good and thorough anti-racism reading list. There are also a number of videos produced by the NZ HRC with informative, interesting videos but with their own layers of multiculturalism and diversity agendas. As I search through the additional resources, admittedly being a lot more thorough than I think the average user of the website will be, I am reminded of the deeply entrenched government mandate of this campaign. There is a desire to encourage people to be good citizens and be educated to prevent future terror attacks and provide a space to live in a "harmonious society." But the messages from the campaign are not intended to create a revolutionary anti-racist society. They merely aim at using institutional diversity to the advantage of the status quo (Ahmed, 2012).

\section{Discussion: Perpetuating Whiteness}

Despite the limitations of the Voice of Racism digital experience, and the additional campaigns associated with Give Nothing to Racism, a number of things can be gained from analysing and understanding this project, both within the context of Aotearoa New Zealand and in other white settler countries. Most importantly, this project serves as an excellent example of what happens when organisations take up anti-racism education through diversity logics as opposed to anti-racist pedagogies that are intended to transform organisations and implement societal action. 
In Canadian culture (and arguably in other countries as well) our solution to racism on a country scale is to respond through diversity program, policies, and initiatives (Birk, 2021). Critical race theory as a theoretical concept has not been as widely adapted and accepted in Canada as it has been in the United States; this difference relates to the cultural and historical conversations about race that happen in our country. The umbrella term of "diversity" is slowly being replaced with the more inclusive though still problematic catch-all phrase "Equity, Diversity, and Inclusion." Through this diversity logic, Canadians (primarily government and institutions) respond to the threat of racism with a heavy dose of diversity education. This response happened on a much larger scale through the global \#BlackLivesMatter movement. When activists and communities spoke about the real-life effects of racism in Black communities in the United States (and beyond), millions of American responded to these realities by purchasing books. We filled our shelves with the uncomfortable truths we couldn't bear to address, and then... nothing (Chudy \& Jefferson, 2021; Jeong et al., 2021). This diversity logic is whiteness's way of absolving systems and institutions from changing.

In her book On Being Included: Racism and Diversity in Institutional Life (2012), Sara Ahmed shows the ways in which diversity, when taken up by large organisations, serves the purpose of engaging whiteness. Through her research with diversity workers, Ahmed shows how the work of the organisation becomes "doing diversity" instead of fundamentally shifting how systems operate. As a result of this work, diversity workers chase diversity up the chain of command instead of creating radical change and thus transforming systems. Following Ahmed's work, in an overly simplified version a diversity logic works like this: A large-scale public event, like a public shooting or a murder by the police, occurs or a video of a racist incident within an institution is released and the public is shocked and horrified. Afterwards, there is widespread media coverage of the event. Government representatives and officials respond with shock and horror and promise some level of change. At times officials deliver on those systemic changes through law reform. Other times, which is most often the case, governments and public bodies respond by investing money in "change". Because governments have reputations and politics to consider, this money is restricted to certain kinds of work (like education instead of advocacy). Organisations take up this newly invested money, with strings, to address the initial issue but also racism more broadly. Often the timeframe on these diversity logics moves quickly, with limited time for reflection and community engagement. The project is then complete and the diversity box is ticked as completed. Limited change has occurred because of the larger logics of the project. Then the cycle repeats itself. In many ways the Voice of Racism project follows this larger diversity logic paradigm.

In 2014, a report entitled Creating Effective Anti-Racism Campaigns, directed to the New Zealand race relations commissioner, the head of race issues at the NZ HRC (Rankine, 2014), outlined several strategies and 14 recommendations for creating effective anti-racism campaigns. The 14 recommendations included ensuring campaigns are well funded and context specific, changing racist behaviour as opposed to beliefs, acknowledging that racism happens differently to different groups and that therefore the campaign should be targeted to specific ethnic groups, 
promoting anti-racism as a norm for the whole society, and countering in-group negative beliefs and creating a balanced emphasis between in-groups and out-groups by also acknowledging the diversity that exists within groups. Most of these recommendations were not adopted by the Voice of Racism campaign. This is a clear example of diversity logic that illustrates Ahmed's (2012) notion that diversity workers end up doing the document instead of doing the work. As Ahmed suggests, diversity is working in our institutions exactly how it is intended to work: as a tokenistic representation of a commitment with little opportunity to create the systemic change necessary to shift the institutional fabric.

This begs the question, why was this initial (2014) report commissioned and recommendations produced if the organisation did not address the majority of these recommendations when it created the Voice of Racism campaign, or any of its other anti-racism campaigns? It makes me wonder, was the Voice of Racism intended to silence the voices of anti-racism? Was the campaign intended to appease the critics who argue that racism is alive and well in New Zealand and to serve as a distraction? Often governments sponsor makeshift solutions under the guise of diversity and education banners that do not always serve the populations they are intended to serve. Or sometimes they serve exactly the way they are supposed to, which is to appease the population without creating any tangible change that fundamentally shifts how anti-racism action happens. I have written elsewhere that diversity cannot be the solution (Birk, 2021). The solution must be to dismantle white supremacy, instead of feeding the diversity corporation by making small public changes that are intended more for appearance than for radical social change.

\section{Conclusion}

In the case of the Voice of Racism project and the Give Nothing to Racism campaign, the information already existed on how to create a more effective campaign, yet the report remained on the shelf instead of informing and affecting the campaign product. Although there is likely a myriad of reasons why the recommendations in this report were not at the forefront of creating these campaigns and several competing factors that informed the project materials, these examples shed light on why diversity logics will remain at the periphery of institutional change until we dismantle the systems of whiteness and call for radically new and revolutionary ways of understanding and engaging with institutional anti-racism.

The Voice of Racism project and the other projects associated with the Give Nothing to Racism campaign follow a classic diversity logic that suggests we are all beautiful and we should celebrate diversity by calling attention to racism and encouraging brave acts on the part of a white saviour who saves the day from racism. These campaigns completely ignore the systemic and institutional foundations that create and sustain white settler societies and further perpetuate them by recentring whiteness for educational purposes instead of dismantling the systems that are at play. As a result, the darkness of the dark blue screen on the Voice of Racism website that I was originally taken aback by has become yet another opportunity to 
reflect back the whiteness of the Pākehā observer who is hungry (hooks, 1992) for a taste of the racism experience.

Throughout this paper my goal was to answer the following question: How is the New Zealand Human Rights Commission curating experiences of racism for the general population through its Voice of Racism online education campaign? Based on my observations I argue that the experiences of racism shared in this online campaign were created by recentring whiteness through three main facets. First, by focusing on racism as an individual act that can be overcome. Second, by satisfying a diversity logic so no one has to take responsibility for racism. The education campaign becomes the action as opposed to dismantling the structures that cause racism. And finally, by allowing racism to perpetuate and thus reinforcing the systems of whiteness that maintain white supremacy.

Author Contributions Not applicable.

Funding Funding for this research was provided by the Social Science and Humanities Research Council of Canada (SSHRC).

Data Availability Not applicable.

Code Availability Not applicable.

\section{Declarations}

Conflict of interest The authors declared that they have no conflict of interest.

\section{References}

Ahmed, S. (2012). On being included: Racism and diversity in institutional life. Duke University Press.

Aikman, P. J., \& Fu, M. (2021). Racism in peril? Mutual aid and solidarity in the face of New Zealand's history of white supremacy against Chinese and Māori. Te Tangi A Te Ruru. https://tetan giateruru.org/2021/04/22/racism-in-peril-mutual-aid-and-solidarity-in-the-face-of-new-zeala nds-history-of-white-supremacy-against-chinese-and-maori/

Azarmandi, M. (2017). Colonial continuities: A study of anti-racism in Aotearoa New Zealand and Spain. Doctoral dissertation, University of Otago.

Bell, D. (1992). Faces at the bottom of the well: The permanence of racism. Basic Books.

Birk, M. (2021, August 05). Critical race theory: 'Diversity' is not the solution, dismantling white supremacy is. The Conversation. https://theconversation.com/critical-race-theory-diversity-isnot-the-solution-dismantling-white-supremacy-is-163398

Came, H., Badu, E., Ioane, J., Manson, L., \& McCreanor, T. (2020). Ethnic pay (dis)parities in the public sector leadership from 2001-2016 in Aotearoa New Zealand. International Journal of Critical Indigenous Studies, 13(1), 70-85.

Chudy, J., \& Jefferson, H. (2021). Support for Black Lives Matter surged last year. Did it last? New York Times. https://www.nytimes.com/2021/05/22/opinion/blm-movement-protests-support.html

Cormack, D., Harris, R., Stanley, J., Lacey, C., Jones, R., \& Curtis, E. (2018). Ethnic bias amongst medical students in Aotearoa/New Zealand: Findings from the Bias and Decision Making in Medicine (BDMM) study. PLoS ONE, 13(8), e0201168-e0201168. https://doi.org/10.1371/journ al.pone. 0201168 
Crenshaw, K. (1991). Mapping the margins: Intersectionality, identity politics, and violence against women of color. Stanford Law Review, 43(6), 1241-1299.

Crothers, C., \& O'Brien, T. (2020). The contexts of the Christchurch terror attacks: Social science perspectives. Kotuitui: New Zealand Journal of Social Sciences, 15(2), 247-259. https://doi.org/ 10.1080/1177083X.2020.1746364

Czyzewski, K. (2011). Colonialism as a broader social determinant of health. The International Indigenous Policy Journal, 2(1), 1-17.

Delgado, R., \& Stefancic, J. (2000). Critical race theory: The cutting edge (2nd ed., pp. 60-70). New York: Temple University Press.

DiAngelo, R. (2018). White fragility: Why it's so hard for White people to talk about racism. Beacon Press.

Dixson, A., \& Rousseau, C. (Eds.). (2006). Critical race theory in education: All God's children got a song. Routledge.

Graham, K. (2010). Beyond redistribution White supremacy and racial justice. Lexington Books.

Health Canada. (2010). First nations, Inuit and aboriginal health: A statistical profile on the health of First Nations in Canada: Determinants of Health, 2006 to 2010. Health Canada.

Hong, J., Chang, R., \& Varley, K. (2021, April). The COVID resilience ranking. Bloomberg. https:// www.bloomberg.com/graphics/covid-resilience-ranking/

hooks, b. (1992). Black looks: Race and representation. New York: Between the Lines Press.

Jeong Perry, A., Scott, B., \& Donnella, L. (Executive producers). (2021, June 9). The racial reckoning that wasn't [Audio podcast episode]. Code Switch, NPR. https://www.npr.org/2021/06/08/10044 67239/the-racial-reckoning-that-wasnt

Marriott, L., \& Sim, D. (2014). Indicators of inequality for Māori and Pacific people. Working Paper 09/2014. Victoria University.

McIntosh, P. (2003). White privilege: Unpacking the invisible knapsack. In S. Plous (Ed.), Understanding prejudice and discrimination (pp. 191-196). McGraw-Hill.

Million, D. (2009). Felt theory: An indigenous feminist approach to affect and history. Wicazo Sa Review, 24(2), 53-76. https://doi.org/10.1353/wic.0.0043

Muru-Lanning, C. (2020, July 2). Endless stories of racism in NZ schools. Re: News. https://www. renews.co.nz/endless-stories-of-racism-in-nz-schools/

New Zealand Human Rights Commission (NZ HRC). (2020a). Give nothing to racism. www.given othing.co.nz

New Zealand Human Rights Commission (NZ HRC). (2020b). Voice of racism. https://voiceofracism. co.nz/

Nielsen. (2021). Te Kaikiri me te Whakatoihara I Aotearoa I te Urutā COVID-19: He Aro Ki Ngā Hapori Haina, Āhia Hoki [Racism and Xenophobia experiences in Aotearoa New Zealand: A focus on Chinese and Asian communities]. New Zealand Human Rights Commission.

Paradies, Y., Ben, J., Denson, N., Elias, A., Priest, N., Pieterse, A., Gupta, A., Kelaher, M., \& Gee, G. (2015). Racism as a determinant of health: A systematic review and meta-analysis. PLoS ONE, 10(9), e0138511-e0138511. https://doi.org/10.1371/journal.pone.0138511

Rankine, J. (2014). Creating effective anti-racism campaigns. https://trc.org.nz/sites/trc.org.nz/files/ 2014\%20Rankine-Creating-effective-anti-racism\%20campaigns.pdf

Razack, S. (1998). Looking white people in the eye: Gender, race, and culture in the courtrooms and classrooms. University of Toronto Press.

Reid, P., Cormack, D., \& Paine, S.-J. (2019). Colonial histories, racism and health: The experience of Māori and Indigenous peoples. Public Health, 172, 119-124. https://doi.org/10.1016/j.puhe. 2019.03.027

Solorzano, D., \& Yosso, T. (2002). Critical race methodology: Counter-storytelling as analytical framework for education research. Qualitative Inquiry, 8(1), 23-44.

Song, J., \& McDonald, C. (2021). Experiences of New Zealand registered nurses of Chinese ethnicity during the COVID-19 pandemic. Journal of Clinical Nursing, 30(5/6), 757-764.

Stats New Zealand. (2021, February 21). Child poverty statistics, corrected. https://www.stats.govt. nz/news/latest-release-of-child-poverty-statistics

Stewart, G. (2020). A typology of Pākehā "whiteness" in education. Review of Education, Pedagogy, and Cultural Studies, 42(4), 296-310. https://doi.org/10.1080/10714413.2020.1773177

Thobani, S. (2007). Exalted subjects: Studies in the making of race and nation in Canada. University of Toronto Press. 
TVNZ. (2020, July 19). Continuous jellyfish sting of racism still causing pain in NZ. https://www. tvnz.co.nz/one-news/new-zealand/continuous-jellyfish-sting-racism-still-causing-pain-in-nzexperts-say-new-campaign-launched

United Nations. (1996). International convention on the elimination of all forms of racial discrimination. https://www.ohchr.org/en/professionalinterest/pages/cerd.aspx

Publisher's Note Springer Nature remains neutral with regard to jurisdictional claims in published maps and institutional affiliations. 